\title{
Psychiatrists' awareness of adherence to antipsychotic medication in patients with schizophrenia: results from a survey conducted across Europe, the Middle East, and Africa
}

\author{
This article was published in the following Dove Press journal: \\ Patient Preference and Adherence \\ 29 January 2013 \\ Number of times this article has been viewed
}

\section{José Manuel Olivares' \\ Köksal Alptekin² \\ Jean-Michel Azorin ${ }^{3}$ \\ Fernando Cañas ${ }^{4}$ \\ Vincent Dubois ${ }^{5}$ \\ Robin Emsley ${ }^{6}$ \\ Philip Gorwood ${ }^{7}$ \\ Peter $\mathrm{M} \mathrm{Haddad}^{8}$ \\ Dieter Naber ${ }^{9}$ \\ George Papageorgiou'10 \\ Miquel Roca"l \\ Pierre Thomas ${ }^{12}$ \\ Guadalupe Martinez ${ }^{13}$ \\ Andreas Schreiner ${ }^{14}$}

'Department of Psychiatry, Hospital Meixoeiro,

Complejo Hospitalario Universitario de

Vigo, Vigo, Spain; ${ }^{2}$ Department of Psychiatry,

Dokuz Eylül University School of Medicine,

Izmir, Turkey; ${ }^{3}$ Department of Psychiatry,

Sainte Marguerite Hospital, Marseille,

France; ${ }^{4}$ Department of Psychiatry,

Hospital Dr R Lafora, Madrid, Spain; ${ }^{5}$ Cliniques

Universitaires St-Luc, Bruxelles, Belgium;

${ }^{6}$ Department of Psychiatry, Faculty of Health

Sciences, University of Stellenbosch, Cape

Town, South Africa; ' Sainte-Anne Hospital,

Paris Descartes University and INSERM

U894, Paris, France; ${ }^{8} \mathrm{G}$ reater Manchester

West Mental Health National Health

Service Foundation Trust and Department

of Psychiatry, University of Manchester,

Manchester, UK; ' ${ }^{9}$ niversitätsklinikum

Hamburg-Eppendorf, Klinik für Psychiatrie

und Psychotherapie, Hamburg, Germany;

${ }^{10}$ Department of Psychiatry, Evangelismos

General Hospital, Athens, Greece; "Unidad

de Psiquiatría, Hospital Juan March, Institut

Universitari d'Investigació en Ciències de la

Salut, Universitat de les Illes Balears, Palma de

Mallorca, Spain; ${ }^{12}$ Department of Psychiatry,

Fontan Hospital CHRU Lille, UDSL, University

North of France, Lille, France; ${ }^{13}$ Medical

Affairs, Janssen, Madrid, Spain; ${ }^{14}$ Medical Affairs,

Janssen, Neuss, Germany

Correspondence: José Manuel Olivares

Department of Psychiatry, Hospital Meixoeiro,

Complejo Hospitalario Universitario de Vigo,

Vigo, Spain

Email jose.manuel.olivares@gmail.com
Background: Nonadherence is common among patients with schizophrenia, although the rates vary according to means of assessment and patient population. Failure to adhere to medication can have a major impact on the course of illness and treatment outcomes, including increasing the risk of relapse and rehospitalization. Understanding psychiatrists' perception of the causes and consequences of nonadherence is crucial to addressing adherence problems effectively.

Methods: The Europe, the Middle East, and Africa (EMEA) Spanish Adherencia Terapéutica en la Esquizofrenia (ADHES) survey was conducted by questionnaire during January-March 2010 among psychiatrists treating patients with schizophrenia in 36 countries. The survey comprised 20 questions. In addition to recording the demographic details of the 4722 respondents $(\sim 12 \%$ response rate), it canvassed their preferred methods of assessing adherence, their perceptions of adherence rates, reasons for nonadherence, and strategies to improve adherence.

Results: Psychiatrists estimated that $53 \%$ of their patients with schizophrenia were partially/ nonadherent during the previous month. They estimated only one-third of patients who deteriorated after stopping medication were able to attribute this to nonadherence. Psychiatrists assessed adherence most often by patient interview. Lack of insight was viewed as the most important cause of medication discontinuation, followed by patients feeling better and thinking their medication unnecessary, and experiencing undesirable side effects. Considerably fewer psychiatrists viewed insufficient efficacy, cognitive impairment, or drug/alcohol abuse as the most important reasons for their patients stopping medication.

Conclusion: Psychiatrists throughout EMEA recognize the impact of partial/nonadherence to medication, with patient enquiry being the most commonly used means of assessment. There remains a need for more proactive management of patients with schizophrenia, particularly in increasing patient insight of their illness in order to improve adherence and minimize the consequences of relapse. Strategies focused on raising awareness of the importance of adherence are also warranted, with the aim of improving patient outcomes in schizophrenia.

Keywords: adherence, schizophrenia, psychiatrist, survey, ADHES

Ensuring patients continue with their medication over the long term is a considerable challenge in psychiatry. ${ }^{1}$ There is a range of often overlapping patient-, treatment-, environment-, and physician-related factors that contribute to partial or nonadherence to medication. ${ }^{2}$ These factors include patients' lack of insight, attitudes toward and previous experiences of medication, comorbidity and symptom severity, the level of social and family support, and the strength of the therapeutic alliance between patient and physician. ${ }^{3}$ 
Health care professionals (HCPs) may positively influence treatment adherence by focusing on the positive aspects of medication, on enhancing insight, and on fostering a positive therapeutic relationship with patients. ${ }^{4}$ There is growing evidence that patients who remain on antipsychotic treatment experience additional benefits beyond symptomatic control. For instance, important health-related quality of life benefits were observed with continuous antipsychotic treatment at 3 years in the European Schizophrenia Outpatients Health Outcomes study. ${ }^{5}$

Partial or nonadherence to medication can have a major impact on the course of illness and treatment outcomes ${ }^{6,7}$ and is associated with an increased risk of relapse, persistence of symptoms, functional impairments, and increased hospitalization. ${ }^{3,8}$ As with other chronic somatic disorders, where as many as $76 \%$ of patients may be nonadherent to medication, ${ }^{9}$ partial or nonadherence to medication is high among patients with psychiatric disorders. Definitions of medication adherence among patients with schizophrenia vary greatly, with reported rates of nonadherence of up to $72 \%$ being reported depending on the definition adopted, the method used to assess adherence, and the patient population evaluated. ${ }^{10}$

Considerable research effort has focused on the impact of psychosocial, pharmacological and programmatic interventions on addressing adherence problems. ${ }^{3}$ A systematic review of 24 controlled trials of psychosocial strategies (largely educational programs) to improve adherence to appointments and medication in patients with psychosis showed that these interventions were effective in both areas. ${ }^{11}$ When nonadherence is due to forgetting medication, supplying medication in a daily compartmentalized medication container can help. ${ }^{3}$ Involving patients in the choice of an antipsychotic and in reviews of effectiveness are important strategies to try to improve adherence. ${ }^{3}$ Some studies, including one conducted among patients with early psychosis, ${ }^{12}$ and a nationwide cohort study in Finland, ${ }^{13}$ have shown significantly lower discontinuation rates for injectable formulations versus their equivalent oral antipsychotics (pooled analysis), with patients in the Finnish cohort almost twice as likely to discontinue oral antipsychotic treatment than treatment with the equivalent injectable formulation. ${ }^{13}$

The Spanish Adherencia Terapéutica en la Esquizofrenia (ADHES) program commenced in 2003 and was aimed at raising awareness of the problem of partial and nonadherence to medication in the treatment of mental illness in Spain. As part of this program, a survey was developed and conducted in Spain to compare patients', relatives', and psychiatrists' opinions on treatment adherence in schizophrenia. ${ }^{14}$ Based on this initiative in Spain, a larger ADHES survey was developed, designed to canvas opinions of psychiatrists treating patients with schizophrenia across Europe, the Middle East, and Africa (EMEA) and ascertain their perceptions of potential reasons for partial or nonadherence to medication among their patients. This manuscript describes the methodology and findings of the ADHES survey of psychiatrists for the whole EMEA region; results from the individual countries within EMEA will be reported elsewhere.

\section{Methods}

The EMEA ADHES schizophrenia survey was developed and conducted as part of the ADHES program in collaboration with a steering committee comprising a group of psychiatrists with an interest in addressing problems of adherence to treatment by patients with schizophrenia.

The surveys were completed anonymously and responses were based on psychiatrists' perceptions. Individual patient information was not collected. The survey comprised a 20-item questionnaire taking approximately 20 minutes to complete. The survey was conducted from January to March 2010 among EMEA psychiatrists (including neurologists with a psychiatric background in Germany) who were treating patients with schizophrenia.

Thirty-nine thousand copies of the survey were prepared for distribution to psychiatrists in 36 countries across the EMEA region. Mostly, the surveys were delivered to psychiatrists by Janssen Pharmaceutica NV personnel or by mail. The psychiatrists to whom the survey was distributed were identified from a database of psychiatrists held by Janssen. In France and Germany the survey was distributed at an open congress. Psychiatrists received a sealed pack containing the survey, a prepaid envelope, and a letter signed by the steering committee explaining the aims of the survey. No further follow-up was made in order to obtain responses from recipients of the survey who did not initially respond. The survey was translated from English into local languages when required. Completed surveys were returned directly and blinded to a third-party agency for data analysis. The survey was not designed to allow statistical analysis of the differences in responses, and the respective versions of the questionnaire were not validated against each other following translation. Interpretation of the results reported here is based on qualitative comparison of the responses obtained.

In addition to recording the gender, age, and practice setting of the respondents, the survey contained questions relating directly to the issue of partial/nonadherence to 
medication in patients with schizophrenia. In recording their responses, psychiatrists were required to estimate (open field) the adherence status of the patients they had seen in the preceding month according to each of the following categories: adherent ( $\geq 90 \%$ recommended treatment dose), partially adherent ( $\geq 30 \%-<90 \%$ recommended treatment dose), or nonadherent ( $<30 \%$ recommended treatment dose). Psychiatrists may have based these responses upon patient interview, clinical experience, their own estimation, or other means. Overall calculations of the proportions of patients who were fully, partially, or nonadherent to treatment were calculated as the arithmetic mean of the values entered for each of the above categories.

Respondents were asked to estimate the proportion of patients, seen by them during the previous month, affected by potential contributors to partial or nonadherence according to three groupings: less than $20 \%$ of patients, between $20 \%$ and $50 \%$ of patients, more than $50 \%$ of patients.

\section{Results}

Results were obtained from 4722 psychiatrists across the EMEA region, representing an estimated response rate of approximately $12 \%$, based on the method and number of surveys distributed. The demographics of respondents in terms of their sex, age, and practice setting are shown in Table 1.

Table I Demographics of respondents $(N=4722)$

\begin{tabular}{ll}
\hline Gender (\%) & \\
Male & 54 \\
Female & 43 \\
Age $(\%)^{\mathrm{b}}$ & \\
$21-30$ years & 10 \\
$31-40$ years & 28 \\
$41-50$ years & 30 \\
$51-60$ years & 23 \\
6I-70 years & 7 \\
Over 70 years & 1 \\
Practice setting (\%), & \\
Academic & 22 \\
Clinical & 32 \\
Tertiary/referral & 13 \\
Private setting & 27 \\
Hospital based & 40 \\
\hline
\end{tabular}

Notes: ${ }^{\mathrm{a}} \mathrm{3} \%$ of respondents to the survey did not provide this information; ${ }^{\mathrm{b}} \mathrm{l} \%$ of respondents to the survey did not provide this information; ' respondents could select all that applied; $\mathrm{d} \mid 4 \%$ of respondents to the survey did not provide this information. Participating countries and number of respondents: Europe (Austria [105], Belgium [164], Denmark [1 15], France [344], Germany [354], Greece [284], Italy [194], The Netherlands [85], Russia [273], Spain [262], Switzerland [144], Turkey [337], United Kingdom [162]); New Europe (Hungary [339], Romania [I I I]); Baltics (Estonia [30], Latvia [94], Lithuania [14I]); Middle East and West Africa (Algeria [400], Morocco [145], Egypt [140], Tunisia [109]), Gulf Cooperation Council (Bahrain, Kuwait, Oman, Qatar, Saudi Arabia, UAE [226]); Near East, West Asia, and African Territories (Cyprus, Iran, Iraq, Jordan, Lebanon, Malta, Sudan, Yemen [164]).
Seventy-six percent of respondents stated that they assessed adherence of their patients at each visit (Figure 1). Fifty-three percent of the patients seen by psychiatrists in the prior month were considered to be either partially or nonadherent (Figure 2). When assessing adherence, asking patients $(77 \%)$ or a close informant $(64 \%)$ were the methods used most often by the respondents (Figure 3).

Forty percent of psychiatrists reported that most of their patients needed reminding by family members/carers to take their medication as prescribed (Figure 4A). Fewer psychiatrists (28\%) thought that most of their patients relied on a nurse, psychiatrist, or professional carer to do so (Figure 4B).

Psychiatrists' views, based on their experience, as to the most important reasons for their patients discontinuing medication are shown in Figure 5. Thirty-six percent of psychiatrists viewed lack of insight as the most important reason for their patients stopping medication. Patients feeling better and thinking it unnecessary to take medication, and undesirable side effects, were viewed as the most important reasons for their patients stopping medication by $26 \%$ and $22 \%$ of psychiatrists, respectively. Five percent or fewer of psychiatrists viewed feeling embarrassed or upset about taking medication, insufficient efficacy, cognitive impairment, or drug/alcohol abuse as the most important reasons for their patients stopping medication.

Switching to or adding a long-acting injectable antipsychotic was the preferred pharmacological approach used by $62 \%$ of psychiatrists for addressing adherence problems (Figure 6).

\section{Discussion}

The EMEA ADHES schizophrenia survey provides insight to the perceptions of a large number of psychiatrists across a

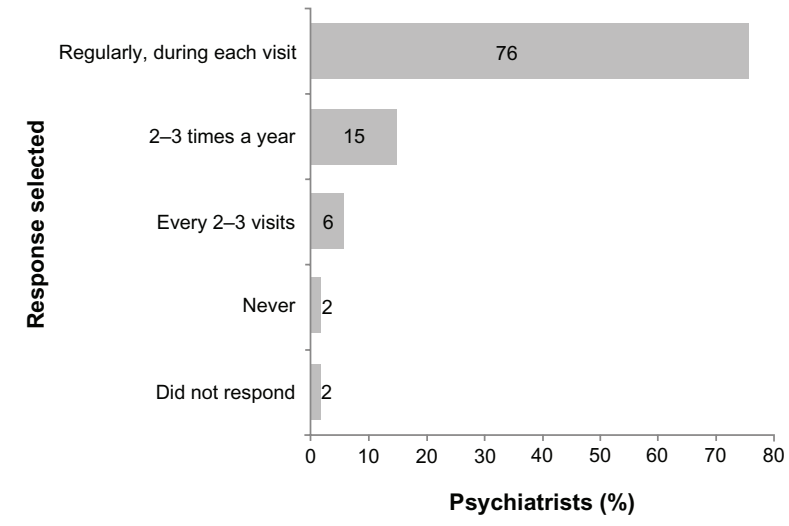

Figure I Psychiatrists' responses regarding the frequency with which they assess adherence in their patients.*

Note: *How often do you assess adherence in your patients? Total exceeds $100 \%$ due to rounding of the individual categories 


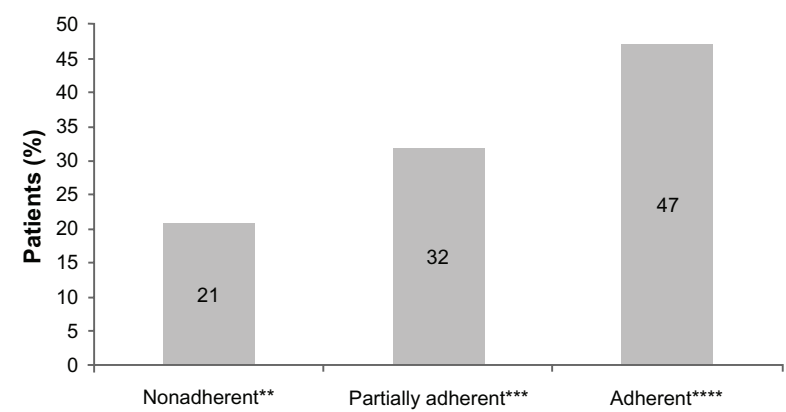

Figure 2 Proportion of patients perceived to be nonadherent, partially adherent, or fully adherent.*

Notes: *Of the patients with schizophrenia you saw in the past month, what percentage do you suspect may have been nonadherent, partially adherent or fully adherent? (21\% of respondents to the survey did not complete this question); $* *<30 \%$ of prescribed doses taken; $* * * \geq 30 \%-<90 \%$ of prescribed doses taken; $* * * * \geq 90 \%$ of prescribed doses taken.

broad geographical area on the assessment, causes, and management of partial and nonadherence to medication in patients with schizophrenia. The response rate was similar to another postal survey conducted among psychiatrists concerning their attitudes toward medication. ${ }^{15}$ There is good agreement among psychiatrists that asking patients explicitly about the amount of medication taken is the preferred method of assessing adherence; however, definitions of medication adherence vary greatly. ${ }^{3}$ Upper and lower limits for the levels of adherence have recently been recommended, to increase comparability across studies. ${ }^{3}$ Arbitrary levels were chosen to assign categories of patient adherence to treatment in the EMEA ADHES survey; nevertheless, the estimated level of partially or nonadherent patients is in line with other assessments of adherence levels among patients with schizophrenia ${ }^{16}$ and similar surveys conducted with smaller groups of psychiatrists. ${ }^{14,17}$ In addition, while psychiatrists also estimated that the majority of their patients may not have stopped medication altogether ( $>5$ consecutive days) without consulting them, a number of patients were perceived to have done so (see Supplementary Figure S1). However, incorrect estimates may result from relying on physician reports of patient decision-making, ${ }^{18}$ and physician perceptions of suspected rather than known nonadherence may not serve as accurate predictors of patient behavior. Indeed, there is evidence to show that psychiatrists can overestimate levels of adherence..$^{19,20}$

The high frequency with which psychiatrists claim to assess adherence suggests that it is considered an important aspect of managing the patient's disorder; however, since the respondents to the survey particularly favor subjective

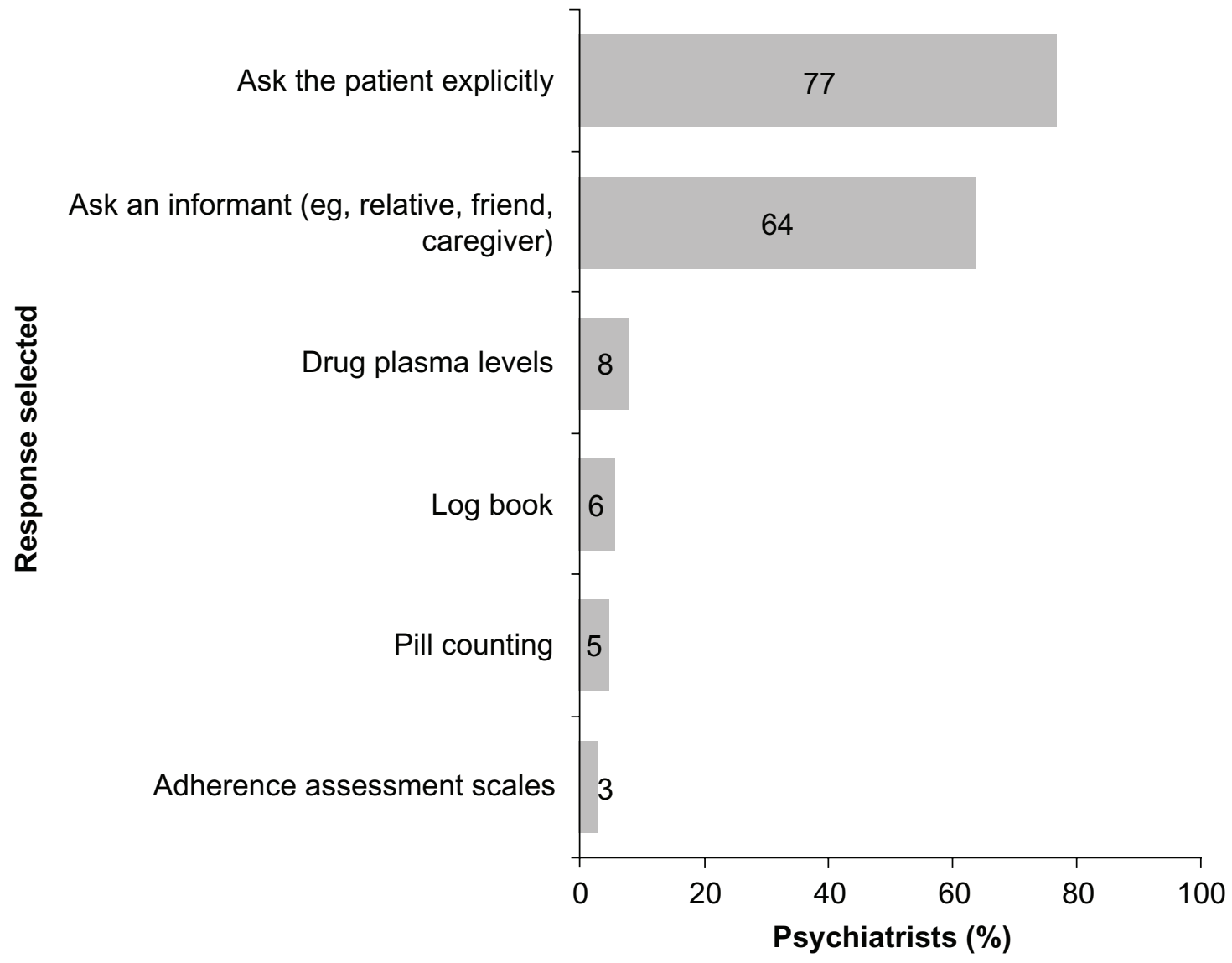

Figure 3 Psychiatrists' views on the approach they normally used to assess adherence (ie, selected the respective methods as their first or second preference).* Note: *During your consultations, which approach do you normally use to assess adherence? Please rank those that you use by frequency, I for most frequent to 6 for least frequent. If you do not use the approach, please leave the box blank. 

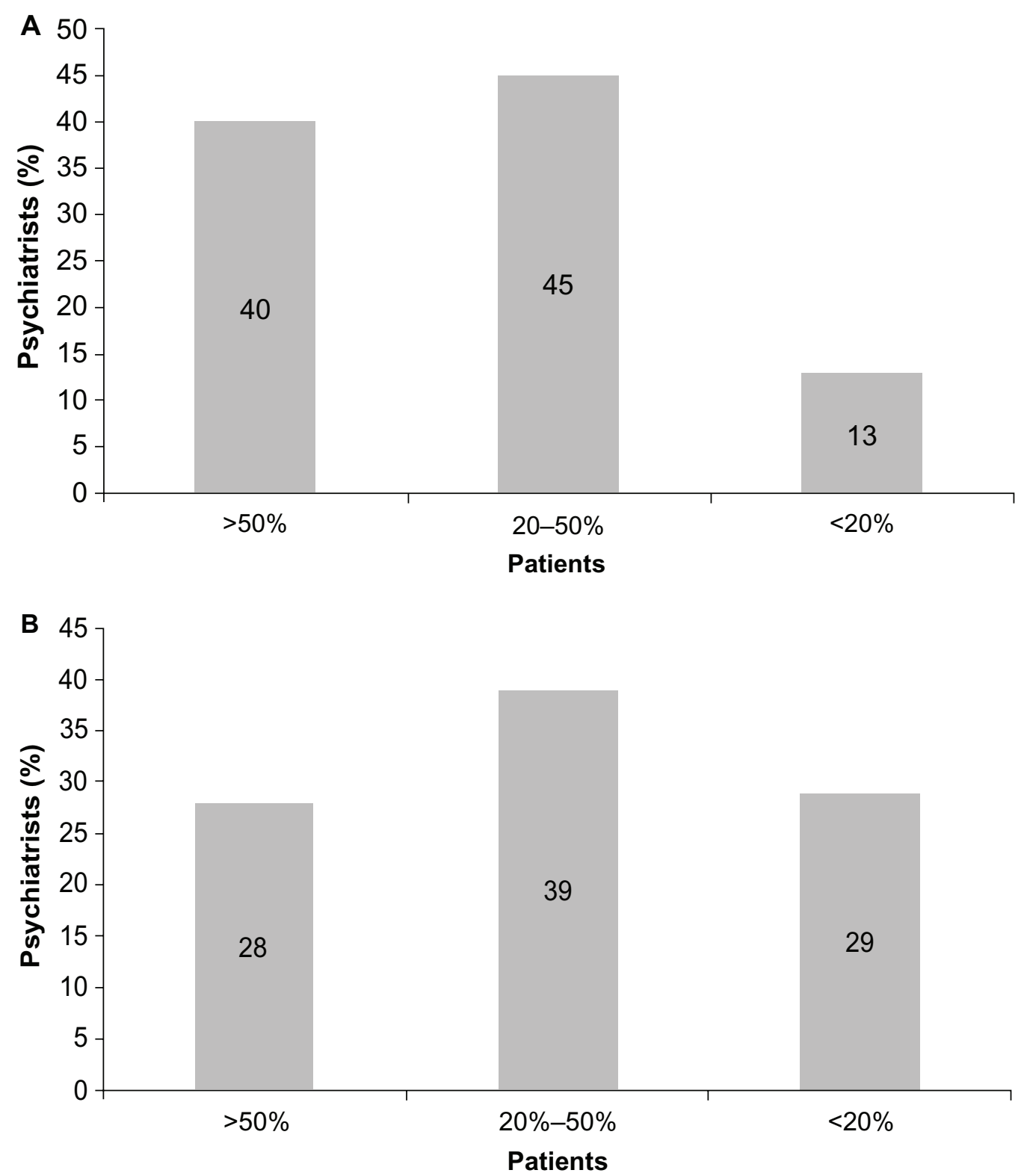

Figure 4 (A) Psychiatrists' views on the burden on family members or carers in reminding patients to take their medication.* (B) Psychiatrists' views on the burden on health care professionals in reminding patients to take their medication. $* *$ ( $\mathbf{A})$ ( $2 \%$ of respondents to the survey did not complete this question). (B) ( $4 \%$ of respondents to the survey did not complete this question).

Note: *What percentage of your patients do you think need family members or carer to remind them to take their medication as prescribed? (2\% of respondents to the survey did not complete this question). ${ }^{* *}$ What percentage of your patients do you think need a nurse, psychiatrist or professional carer to remind them to take their medication as prescribed? ( $4 \%$ of respondents to the survey did not complete this question).

methods over potentially more accurate methods, such as the use of adherence scales, pill counts, or drug plasma level monitoring, and given that all methods of assessment can underestimate the true extent of poor adherence, ${ }^{19}$ the extent of partial and nonadherence may be even greater. It is important that when clinicians enquire about adherence they do so in a nonjudgmental way that encourages patients to discuss adherence openly. ${ }^{21}$

The survey findings highlight the extent to which patients are perceived to rely on a HCP, and to an even greater extent on family members/carers, to remind them to take their medication as prescribed, illustrating the additional burden nonadherence to medication by patients places on those around them. ${ }^{8}$

The impact of lack of insight on adherence is highlighted in the current survey since psychiatrists considered, in their experience, it was the most important reason for patients discontinuing medication. Moreover, $23 \%$ of psychiatrists perceived that most of their patients showed lack of insight in the previous month (see Supplementary Figures). Poor insight is a common feature of schizophrenia and has a complex relationship to other symptoms of the illness. ${ }^{22}$ Patients with a lack 


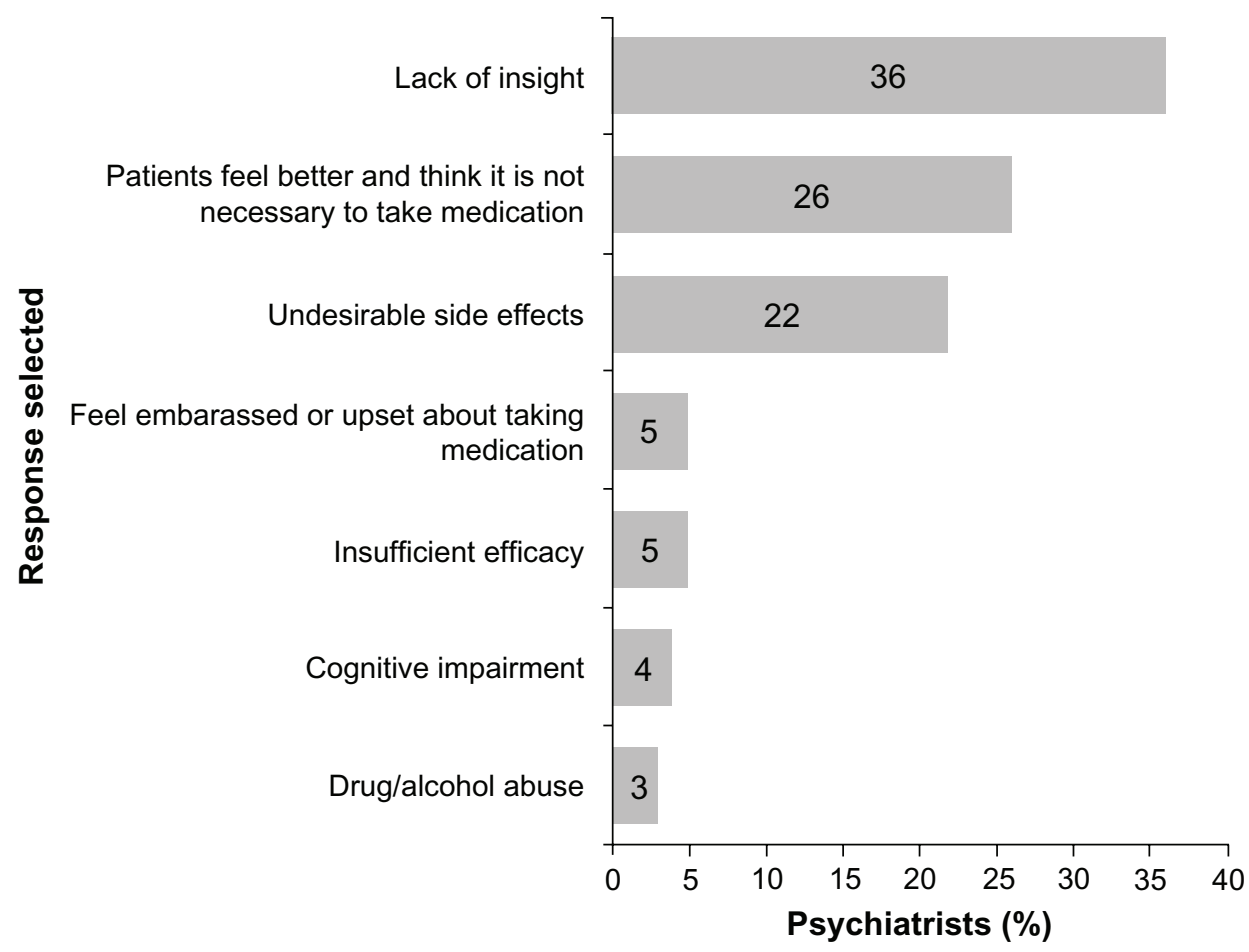

Figure 5 Psychiatrist's views on the most important reason for their patients discontinuing medication.*

Note: *What is, in your experience, the most important reason for your patients to discontinue medication?

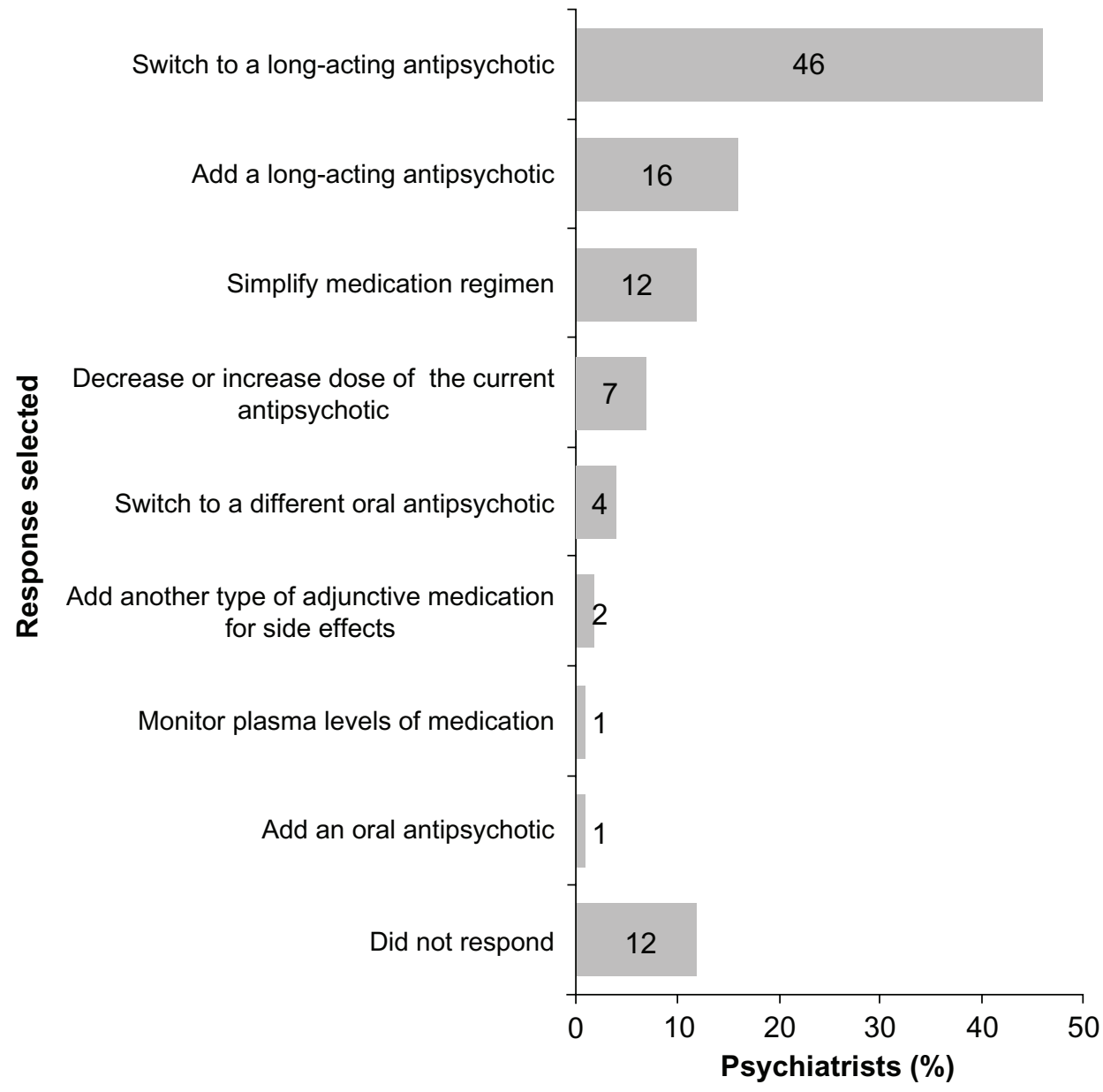

Figure 6 Psychiatrists' views on the preferred pharmacological approach they would use to address an adherence problem in their patients.*

Notes: Due to rounding of raw data, results add up to $>100 \%$. *Please indicate which one of the following pharmacological strategies you would preferentially use to address an adherence problem in your patients with schizophrenia. 
of insight usually do not recognize that they are ill, while those with partial insight demonstrate poor awareness of being ill and the need for medication..$^{23}$ One assessment suggested that between $50 \%$ and $80 \%$ of patients with schizophrenia do not believe they have a disorder. ${ }^{24}$ Recent research has illustrated the impact that poor insight and irregular daily routines have on medication adherence, with poor insight shown to increase the risk of nonadherence twofold. ${ }^{25}$ Thus, poor insight can prevent treatment, destabilize the patient, and lead to a poor prognosis., ${ }^{2,26}$ Three out of four psychiatrists who responded to the EMEA ADHES survey perceived that most of their patients were unable to attribute clinical deterioration to medication nonadherence (see supplementary Figure S2) and two out of five psychiatrists considered that most of their patients understood there is a risk of relapse if they did not take their medication regularly (see supplementary Figure S3).

Respondents to the survey (26\%) also considered their patients feeling better and thinking it unnecessary to take medication was a relatively important reason for patients discontinuing medication. This factor has been shown to influence treatment adherence more widely, ${ }^{27}$ particularly following recovery from a first psychotic episode. ${ }^{28}$ Irregular daily routine or difficult living circumstances were also considered by psychiatrists to be important reasons for partial/ nonadherence to treatment among most of their patients during this period. Irregular daily routines can include aspects such as shift work, unemployment, and irregularities in family relationships and environment. Unemployment and social isolation have been shown to be strongly associated with nonadherence, ${ }^{29}$ while nonsupportive family structures were predictive of poor adherence in first-episode psychosis. ${ }^{30}$

The occurrence of undesirable side effects was cited as an important reason for their patients discontinuing their medication. This is consistent with other studies in which this factor was found to be associated with nonadherence. ${ }^{28,31}$ When considering the impact of treatment side effects on adherence, the attitudes of physicians toward the tolerability of antipsychotics must be borne in mind since these have previously been shown to be markedly different to those of the general population. ${ }^{32}$

Among a variety of pharmacological options available to address adherence problems in their patients, the majority of psychiatrists favored switching to or adding a long-acting antipsychotic; however, it is unclear whether this preference occurs in clinical practice since in many countries fewer than $20 \%$ of individuals with schizophrenia receive long-acting or depot antipsychotics. ${ }^{15}$ This finding may be partly influenced by attitudes toward treatment and awareness of the available options. Before a decision can be made on the most appropri- ate treatment strategy, some understanding of the possible reasons for nonadherence is required through discussion with the patient, which must be weighed against the likelihood that individual adherence problems are influenced by multiple and often different factors.

\section{Limitations}

The results reported and discussed here are based on the clinical opinions of the psychiatrists surveyed. The psychiatrists to whom the surveys were distributed were identified from a database held by Janssen. A large proportion of the psychiatrists surveyed here worked in a hospital setting and therefore may be more likely to have treated seriously ill patients or patients with suboptimal adherence. However, the demographics of the patients (for instance, whether they were living independently or providing their own care) and clinical status of the patients to whom the psychiatrists' answers related, are not known. The psychiatrists who responded may have a greater awareness of adherence problems and a more pessimistic view of the extent of partial/nonadherence by patients with schizophrenia than the broader population of psychiatrists across the EMEA region. The extent to which the demographics (in terms of gender, age, and practice setting) of the respondents may differ from those of psychiatrists across the EMEA region as a whole, and the impact on the survey results, are not known.

\section{Conclusion}

The EMEA ADHES schizophrenia survey is the first survey of the perceptions of the assessment, causes, and management of partial and nonadherence to medication within such a large number of psychiatrists across EMEA. The survey findings confirm psychiatrists perceive that partial and nonadherence to treatment remains a considerable problem for patients with schizophrenia. Psychiatrists consider assessment of adherence to be an important aspect of patient management and show considerable agreement on the main reasons that influence patient adherence.

The survey findings suggest that focusing on factors such as improving patient insight and patients' daily routine and living circumstances may lead to a reduction in the high level of partial or nonadherence among patients reported here. Similarly, steps to ensure that appropriate pharmacological treatment options are offered to patients, and that patients continue with their medication even when they feel better, are also warranted if improved clinical outcomes in the treatment of patients with schizophrenia are to be achieved. 


\section{Acknowledgments}

The EMEA ADHES survey and this manuscript were supported by funding from Janssen Pharmaceutica NV. Medical writing support was provided by ApotheCom ScopeMedical, Sevenoaks, UK, funded by Janssen. All authors approved the design and reviewed the results of the survey. All authors developed the draft of the manuscript, participated in subsequent revisions, and read and approved the final manuscript.

\section{Disclosure}

GM and AS are employees of Janssen Pharmaceutica NV, Medical Affairs. JMO, KA, JMA, FC, VD, RE, PG, PMH, DN, GP, MR, and PT have been members of advisory boards, involved in designing and participating in clinical trials, or received educational grants for research, honoraria, and travel from Janssen as well as other pharmaceutical companies.

The authors' involvement in the ADHES program, described in this paper, was part of paid consultancy work with Janssen, who provided travel expenses for authors to attend advisory boards where the project was discussed. Authors were not remunerated for their involvement in the preparation of this manuscript.

\section{References}

1. Kane JM. Review of treatments that can ameliorate nonadherence in patients with schizophrenia. J Clin Psychiatry. 2006;67(Suppl 5): 9-14.

2. Llorca PM. Partial compliance in schizophrenia and the impact on patient outcomes. Psychiatry Res. 2008;161:235-247.

3. Velligan DI, Weiden PJ, Sajatovic M, et al. Expert Consensus Panel on Adherence Problems in Serious and Persistent Mental Illness: The expert consensus guideline series: adherence problems in patients with serious and persistent mental illness. J Clin Psychiatry. 2009;70(Suppl 4):1-46.

4. Kikkert MJ, Schene AH, Koeter MWJ, et al. Medication adherence in schizophrenia: exploring patients', carers' and professionals' views. Schizophr Bull. 2006;32:786-794.

5. Alonso J, Croudace T, Brown J, et al. Health-related quality of life (HRQL) and continuous antipsychotic treatment: 3 -year results from the Schizophrenia Health Outcomes (SOHO) study. Value Health. 2009;12:536-543.

6. Keith SJ, Kane JM. Partial compliance and patient consequences in schizophrenia: our patients can do better. J Clin Psychiatry. 2003;64: 1308-1315.

7. Masand PS, Roca M, Turner MS, Kane JM. Partial adherence to antipsychotic medication impacts the course of illness in patients with schizophrenia: a review. Prim Care Companion J Clin Psychiatry. 2009;11:147-154.

8. Novick D, Haro JM, Suarez D, Perez V, Dittmann RW, Haddad PM. Predictors and clinical consequences of non-adherence with antipsychotic medication in the outpatient treatment of schizophrenia. Psychiatry Res. 2010;176:109-113.

9. Cramer JA, Rosenheck R. Compliance with medication regimens for mental and physical disorders. Psychiatr Serv. 1998;49:196-201.

10. Lacro JP, Dunn LB, Dolder CR, Leckband SG, Jeste DV. Prevalence of and Risk factors for medication nonadherence in patients with schizophrenia: a comprehensive review of recent literature. J Clin Psychiatry. 2002;63:892-909.

11. Nosé M, Barbui C, Gray R, Tansella M. Clinical interventions for treatment non-adherence in psychosis: meta-analysis. Br J Psychiatry. 2003;183:197-206.
12. Emsley R, Oosthuizen P, Koen L, Niehaus DJH, Medori R, Rabinowitz J. Oral versus injectable antipsychotic treatment in early psychosis: post hoc comparison of two studies. Clin Ther. 2008;30:2378-2386.

13. Tiihonen J, Haukka J, Taylor M, Haddad PM, Patel MX, Korhonen P. A nationwide cohort study of oral and depot antipsychotics after first hospitalization for schizophrenia. Am J Psychiatry. 2011;168:603-609.

14. Giner J, Cañas F, Olivares JM, et al. Treatment adherence in schizophrenia. A comparison between patient's, relative's and psychiatrist's opinions. Actas Esp Psiquiatr. 2006;34:386-392.

15. Jaeger M, Rossler W. Attitudes towards long-acting depot antipsychotics: a survey of patients, relatives and psychiatrists. Psychiatry Res. 2010;175:58-62.

16. Marder SR. Overview of partial compliance. J Clin Psychiatry. 2003; 64(Suppl 16):3-9.

17. Turner M, Masand P, Roca M, Kane J. Results of a study on psychiatrists' perceptions of adherence to medication among patients with schizophrenia: the ADHES survey. Eur Neuropsychopharmacol. 2007;17(Suppl 4):S455-S456.

18. Rosenheck R, Chang S, Choe Y, et al. Medication continuation and compliance: a comparison of patients treated with clozapine and haloperidol. J Clin Psychiatry. 2000;61:382-386.

19. Velligan DI, Lam Y-WF, Glahn DC, et al. Defining and assessing adherence to oral antipsychotics: a review of the literature. Schizophr Bull. 2006;32:724-742.

20. Velligan DI, Wang M, Diamond P, et al. Relationships among subjective and objective measures of adherence to oral antipsychotic medications. Psychiatric Services. 2007;58:1187-1192.

21. Cañas F, Alptekin K, Azorin JM, et al. Improving treatment adherence in your patients with schizophrenia: the STAY initiative. Clin Drug Invest. In press. 2012.

22. Sevy S, Nathanson K, Visweswaraiah H, Amador X. The relationship between insight and symptoms in schizophrenia. Compr Psychiatry. 2004;45:16-19.

23. Aguglia E, De Vanna M, Onor ML, Ferrara D. Insight in persons with schizophrenia: effects of switching from conventional neuroleptics to atypical antipsychotics. Prog Neuropsychopharmacol Biol Psychiatry. 2002;26:1229-1233.

24. Dam J. Insight in schizophrenia: a review. Nord $J$ Psychiatry. 2006;60:114-120.

25. Novak-Grubic V, Tavcar R. Predictors of noncompliance in males with first-episode schizophrenia, schizophreniform and schizoaffective disorder. Eur Psychiatry. 2002;17:148-154.

26. Lysaker PH, Buck KD, Salvatore G, Popolo R, Dimaggio G. Lack of awareness of illness in schizophrenia: conceptualizations, correlates and treatment approaches. Expert Rev Neurother. 2009;9:1035-1043.

27. Fleischhacker WW, Eerdekens M, Karcher K, et al. Treatment of schizophrenia with long-acting injectable risperidone: a 12-month open-label trial of the first long-acting second-generation antipsychotic. J Clin Psychiatry. 2003;64:1250-1257.

28. Perkins DO, Gu H, Weiden PJ, McEvoy JP, Hamer RM, Lieberman JA, on behalf of the Comparison of Atypicals in First Episode study group. Predictors of treatment discontinuation and medication nonadherence in patients recovering from a first episode of schizophrenia, schizophreniform disorder, schizoaffective disorder: A randomized double-blind, flexible-dose, multicenter study. J Clin Psychiatry. 2008;69: 106-113.

29. Tacchi M-J, Scott J. Improving Adherence in Schizophrenia and Bipolar Disorders. Chichester, England: John Wiley and Sons Ltd; 2005.

30. Rabinovitch M, Béchard-Evans L, Schmitz N, Joober R, Malla A. Early predictors of nonadherence to antipsychotic therapy in first-episode psychosis. Can J Psychiatry. 2009;54:28-35.

31. Robinson DG, Woerner MG, Alvir JM, Bilder RM, Hinrichsen GA, Lieberman JA. Predictors of medication discontinuation by patients with first-episode schizophrenia and schizoaffective disorder. Schizophr Res. 2002;57:209-219.

32. Helbling J, Ajdacic-Gross V, Lauber C, Weyermann R, Burns T, Rössler W. Attitudes to antipsychotic drugs and their side effects: a comparison between general practitioners and the general population. BMC Psychiatry. 2006;6:42. 


\section{Supplementary figures}

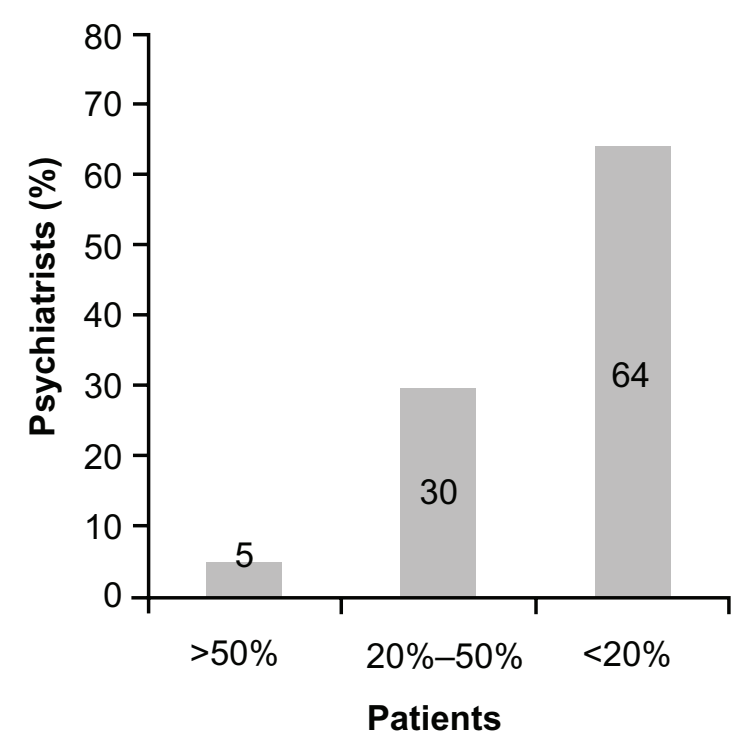

Figure SI What percentage of your patients may have stopped medication altogether ( $>5$ consecutive days) without consulting you?

Note: $1 \%$ of respondents to the survey did not complete this question.

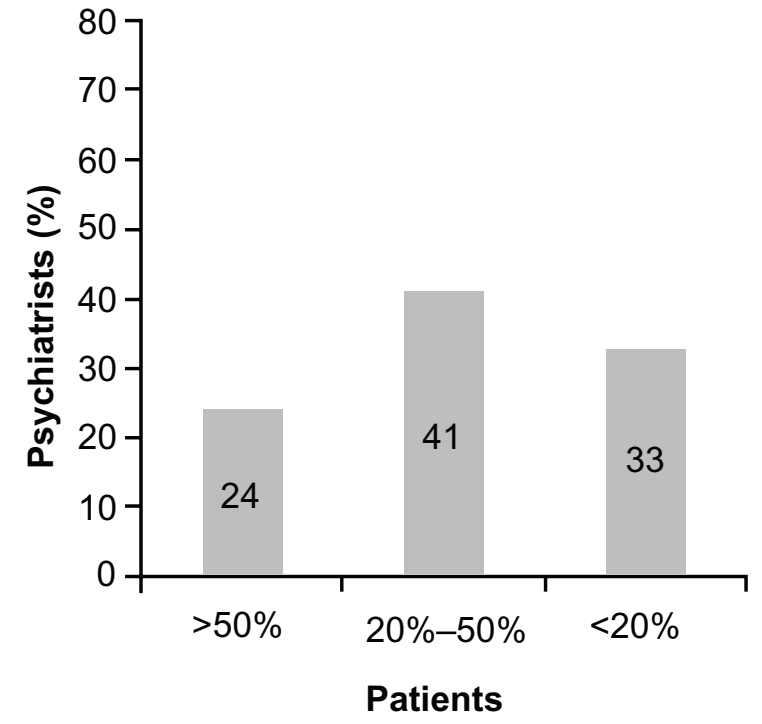

Figure S3 What percentage of your patients have told you that they understand there is a risk of relapse if they don't take their medication regularly? Note: $2 \%$ of respondents to the survey did not complete this question.

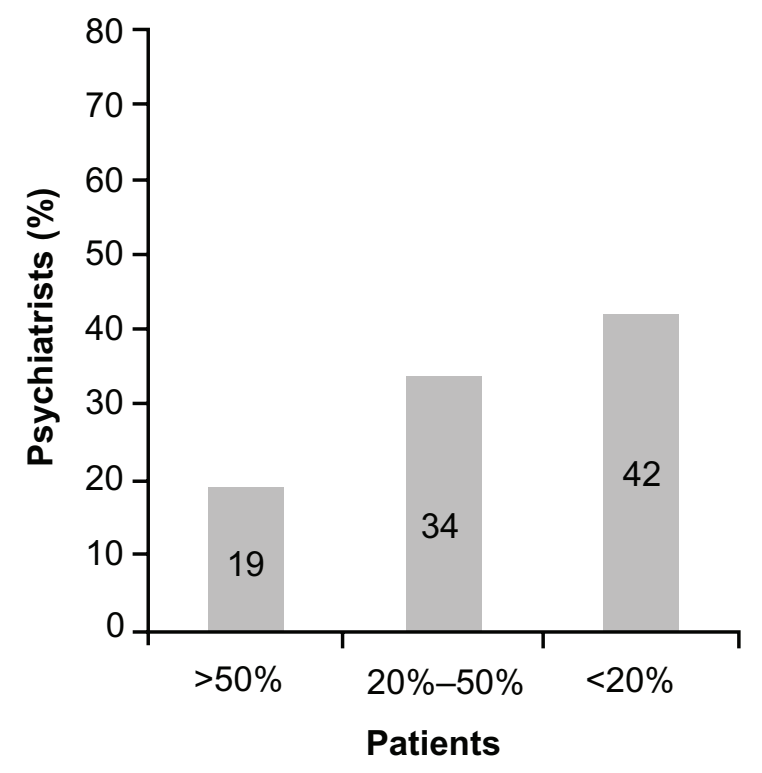

Figure S2 What percentage of your patients who deteriorated after stopping medication were able to attribute this to medication nonadherence? Note: $5 \%$ of respondents to the survey did not complete this question.

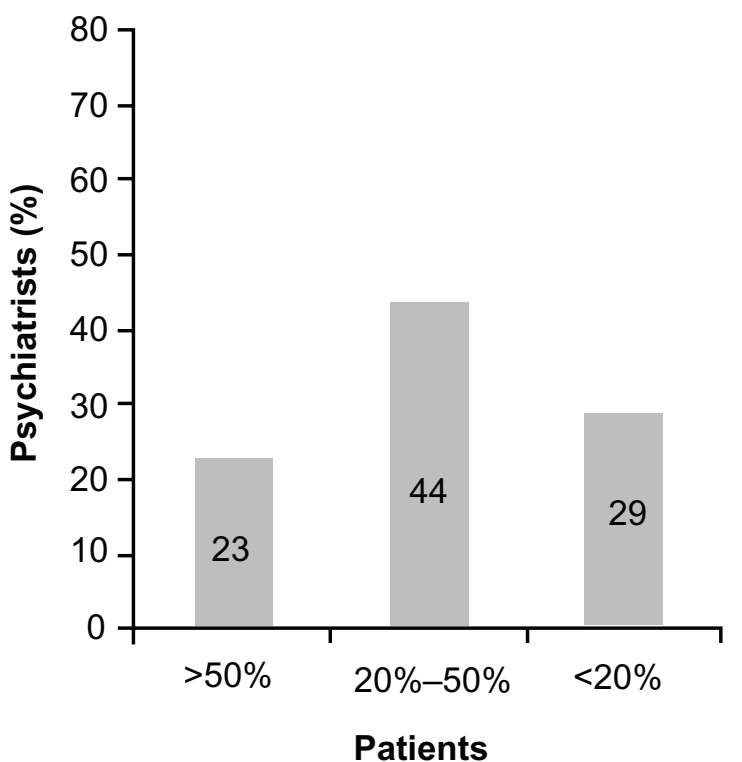

Figure S4 What percentage of your patients show, or has at any time in the past month, shown some lack of insight?

Note: $4 \%$ of respondents to the survey did not complete this question. 


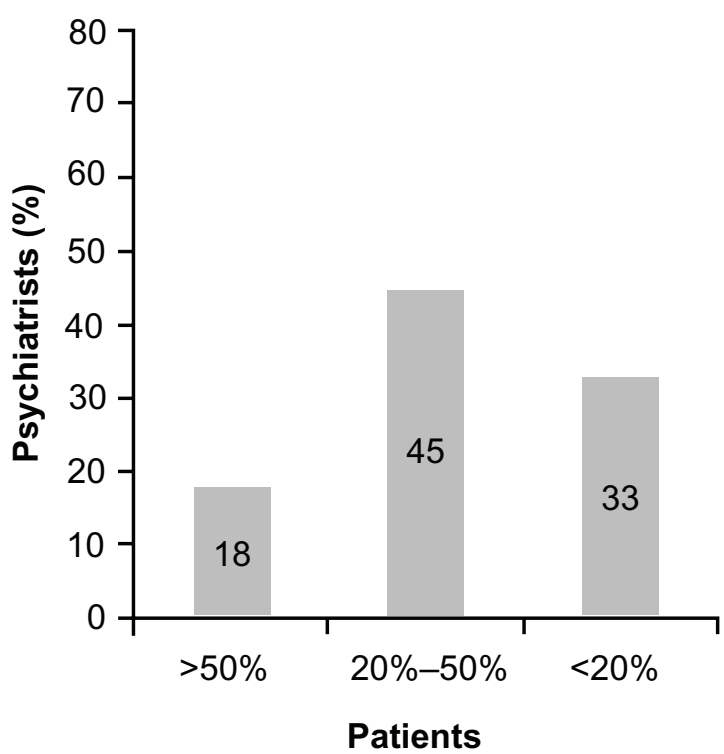

Figure S5 What percentage of your patients has an irregular daily routine or lives in circumstances that might affect proper daily compliance with their treatment? Note: $4 \%$ of respondents to the survey did not complete this question.

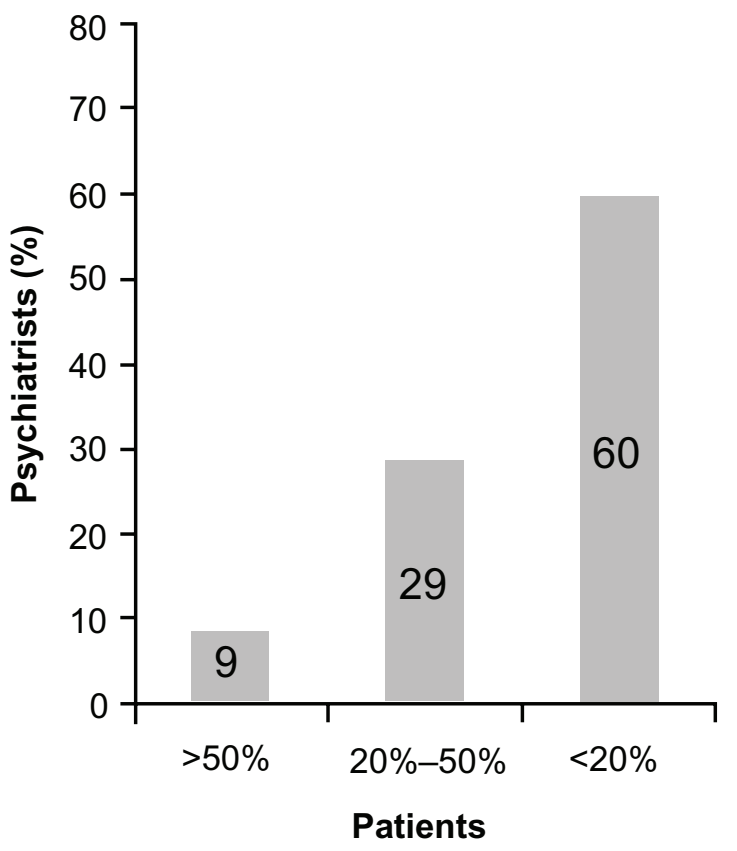

Figure S6 When your patients felt better, what percentage said that medication was unnecessary and stopped taking it?

Note: $2 \%$ of respondents to the survey did not complete this question.

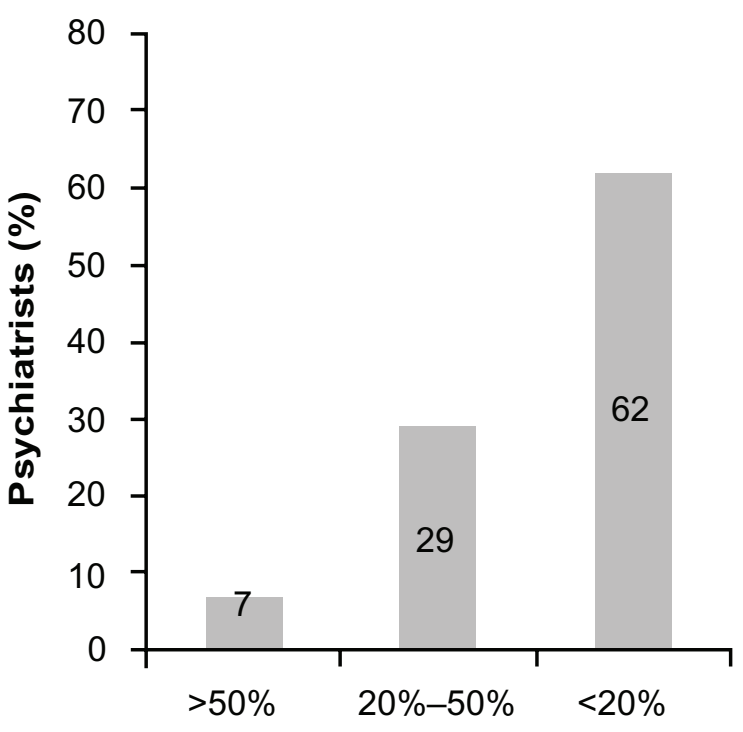

\section{Patients}

Figure S7 What percentage of your patients has not taken their medication due to psychotic symptoms?

Note: $2 \%$ of respondents to the survey did not complete this question.

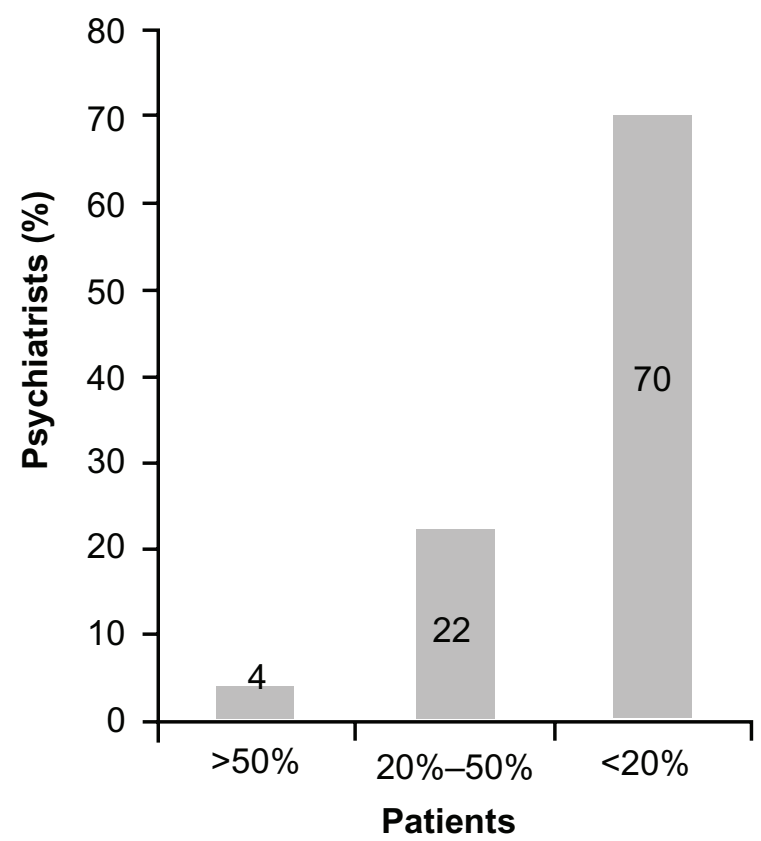

Figure S8 What percentage of your patients has not taken their medication due to cognitive impairment?

Note: $4 \%$ of respondents to the survey did not complete this question. 


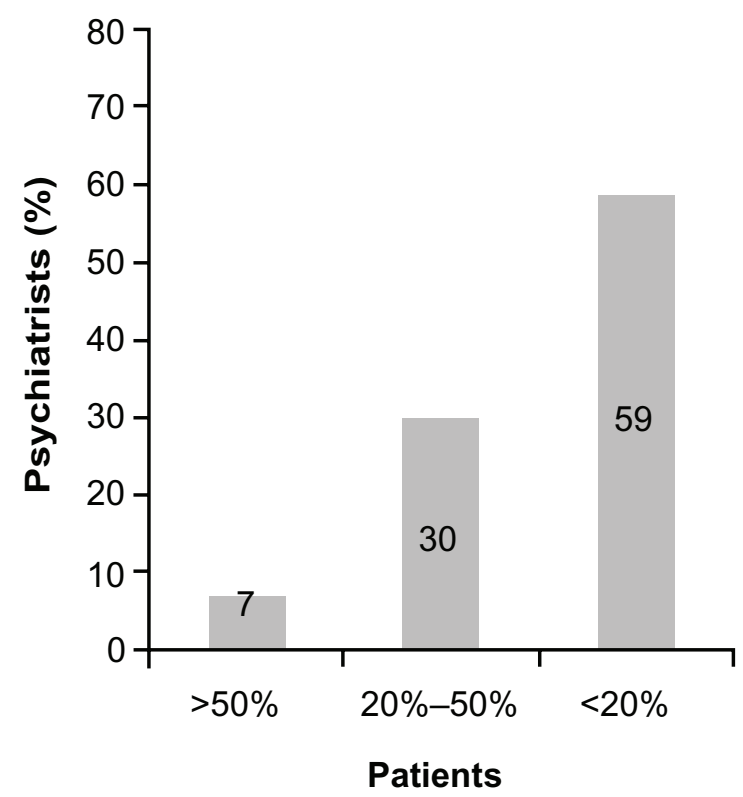

Figure S9 What percentage of your patients stopped taking their medication due to undesirable side effects?

Note: $4 \%$ of respondents to the survey did not complete this question.

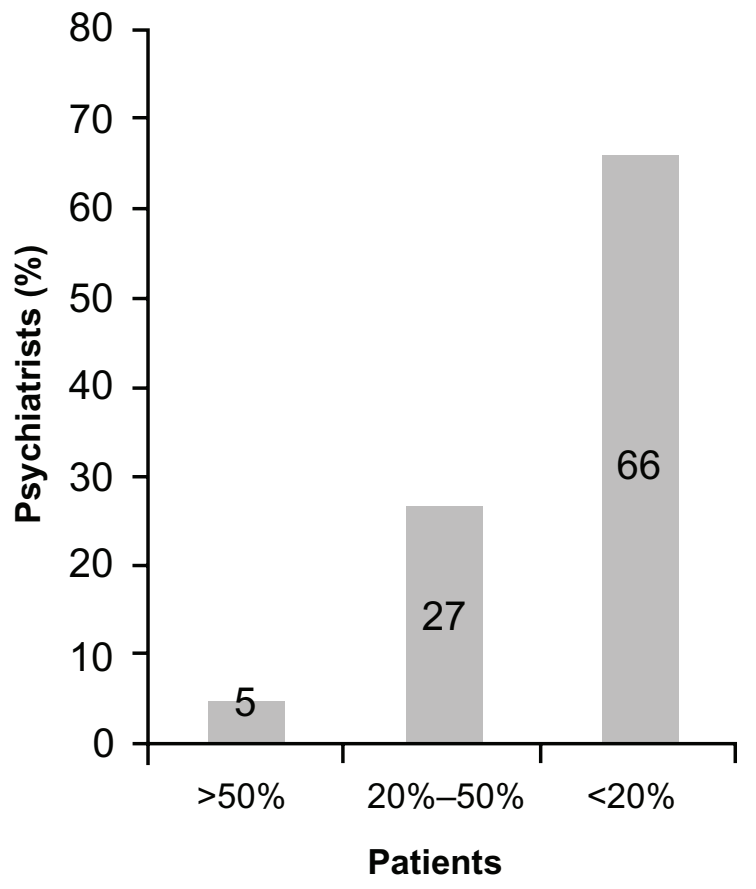

Figure SIO What percentage of your patients has a drug or alcohol consumption that may have impacted on their adherence to medication?

Note: $2 \%$ of respondents to the survey did not complete this question.

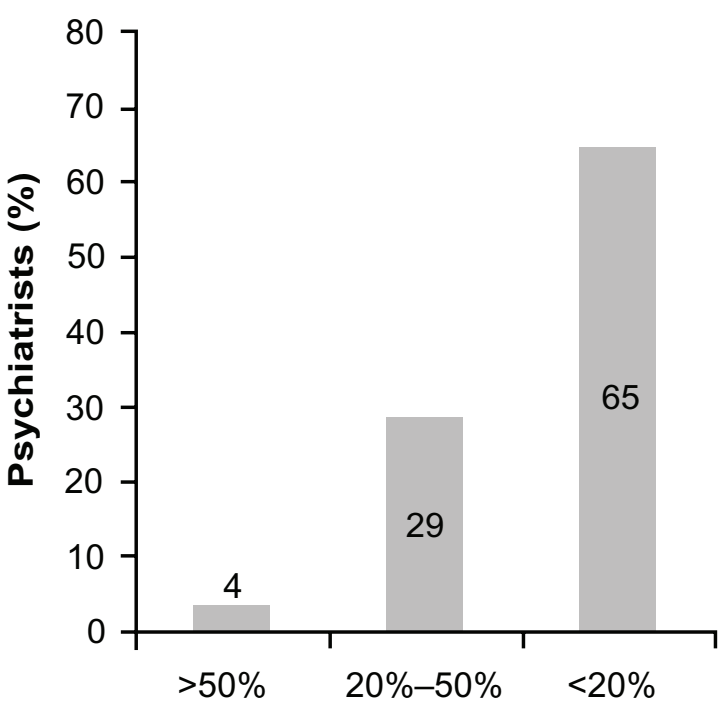

Patients

Figure SII What percentage of your patients have families with negative views about medication?

Note: $2 \%$ of respondents to the survey did not complete this question.

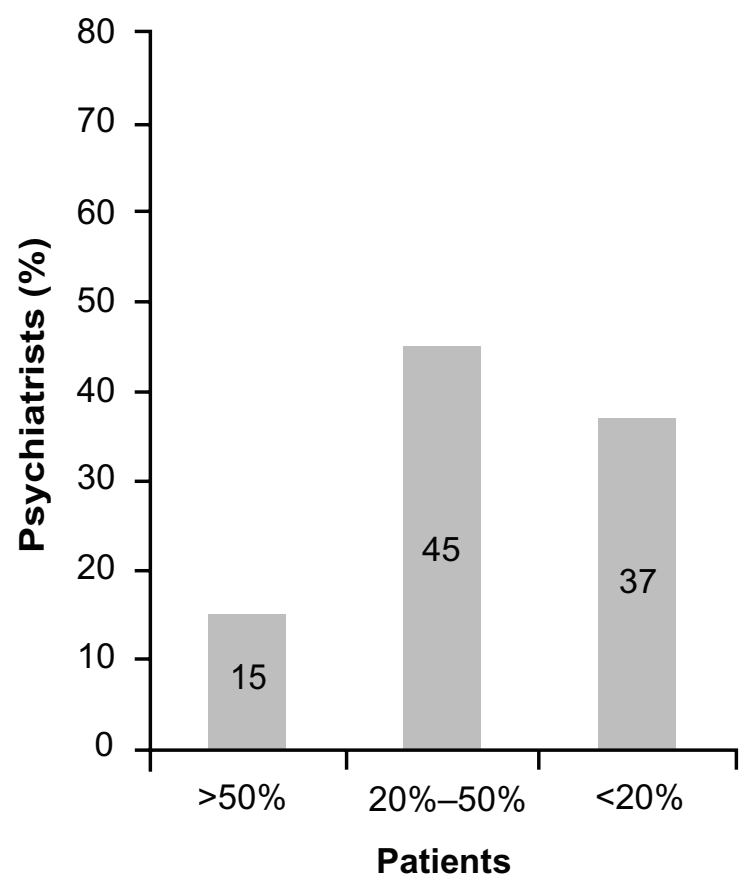

Figure S I 2 What percentage of your patients have their own negative beliefs about their medication?

Note: $3 \%$ of respondents to the survey did not complete this question. 


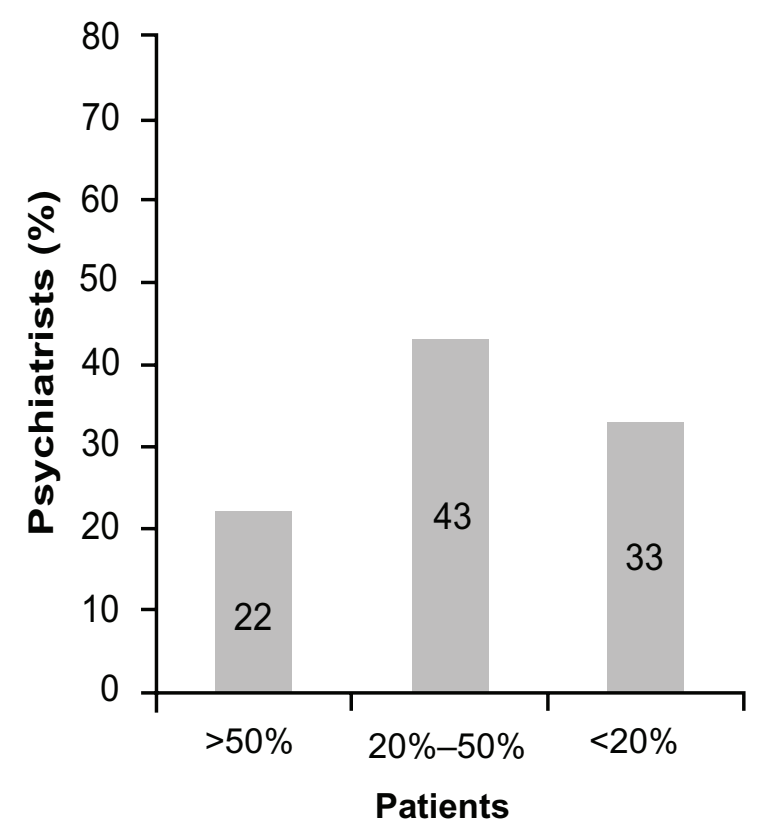

Figure SI 3 What percentage of your patients has at any time felt embarrassed or upset at having to take tablets every day for their illness?

Note: $2 \%$ of respondents to the survey did not complete this question.

\section{Publish your work in this journal}

Patient Preference and Adherence is an international, peer-reviewed, open access journal focusing on the growing importance of patient preference and adherence throughout the therapeutic continuum. Patient satisfaction, acceptability, quality of life, compliance, persistence and their role in developing new therapeutic modalities and compounds to optimize clinical outcomes for existing disease states are major areas of interest. This journal has been accepted for indexing on PubMed Central. The manuscript management system is completely online and includes a very quick and fair peer-review system. Visit http://www.dovepress.com/ testimonials.php to read real quotes from published authors. 